\title{
La modelización tópica y el ethos: lo que de Eva Perón dicen sus propios discursos
}

\author{
The Topical Modelization and Ethos: What Eva Perón's \\ Discourses say of Herself
}

\section{Silvia Ramírez Gelbes}

Universidad de Buenos Aires

Universidad de San Andrés

sramirezgelbes@gmail.com

\begin{abstract}
Resumen
La modalización discursiva es la manifestación de la actitud del enunciador respecto de su enunciado o de su destinatario por medio de diferentes estrategias, como la entonación o el empleo de palabras axiológicas. En este trabajo, introducimos la noción de modalización tópica, entendiéndola como la evocación en el enunciado de universos ordinarios o de universos extraordinarios. Desde nuestro punto de vista, esta modalización contribuye a conformar una imagen neutra o una imagen intensificada del enunciador.

Para demostrarlo, hemos aplicado esta noción a los discursos que Eva Perón pronunció para el Día del Trabajador durante cuatro años consecutivos. Y hemos observado que, en solidaridad con otras estrategias de refuerzo, la modalización tópica realizada en esos discursos configura la imagen de un enunciador enfático, vehemente y extremo.
\end{abstract}

Palabras clave: modelización, tópicos, ethos, imagen, Eva Perón.

\begin{abstract}
Discourse modelization shows speaker's attitudes about his statements or his audiences through many strategies, such as intonation or axiological words using. In this paper, we introduce the notion of topical modalization, understood as the evocation, in discourse, of ordinary or extraordinary universes. From our point of view, this modalization contributes to form a neutral or intensified image of speaker himself. To demonstrate this, we applied this notion to Eva Peron's speeches for Labor Day in four consecutive years. And we found that, complementary with other support strategies, topical modalization made up the image of a emphatic, passionate and extreme speaker.
\end{abstract}


Keywords: modelization, topics, ethos, image, Eva Peron.

\section{Introducción}

El ejercicio de la palabra, se sabe, motoriza en el individuo la construcción de una cierta imagen ${ }^{1}$ de sí. Esta construcción de la imagen del enunciador por medio del discurso es lo que se ha llamado ethos discursivo. En las figuras políticas, la construcción de esa imagen responde a un cierto programa relativo al proyecto argumentativo del enunciador, entendiendo que ese programa se centra en la persuasión.

Tal como lo plantea Aristóteles, para persuadir, no es suficiente con que el argumento sea convincente y fidedigno: es fundamental la actitud de quien produce el discurso y "que dé la impresión a los receptores de que se encuentra en determinada disposición respecto de ellos" (1998, p. 139). Una forma de mostrar esa actitud es el tipo de asociaciones semánticas que el enunciador pone en juego en su discurso: asociaciones con universos cotidianos o asociaciones con universos excepcionales. Para decirlo de otro modo, la clase de campos de significado - neutros o hiperbólicos - a los que alude un discurso - esto es, la modalización tópica, concepto que introducimos aquí- colabora en la conformación de una cierta imagen del enunciador. Es a partir de esta hipótesis que produciremos nuestro análisis.

En este trabajo, nos proponemos demostrar que la recurrencia de ciertas asociaciones semánticas - que llamaremos tópicos- en los discursos de Eva Perón permite configurar una cierta imagen de la líder política. Para hacerlo, estudiaremos los textos de los cuatro discursos que ella pronunciara para el Día del Trabajador ( $1^{\circ}$ de mayo) de los años 1949, 1950, 1951 y 1952.

En lo que sigue, nos ocupamos, en primer lugar, de desarrollar el concepto de ethos; en segundo lugar, delimitamos la noción de tópico al tiempo que definimos el concepto de modalización tópica; en tercer lugar, buscamos los tópicos recurrentes en los discursos seleccionados; y, finalmente, relacionamos esa recurrencia con la conformación de una cierta imagen discursiva en los discursos seleccionados de Eva Perón.

\section{El ethos}

Según Aristóteles (1998), para que un discurso sea creíble, el tema y el estilo han de estar armonizados de modo que resulten apropiados al ethos. Lo que el autor del discurso

\footnotetext{
${ }^{1}$ En este trabajo, hablaremos indistintamente de ethos y de imagen.
} 
quiere ser lo deja entender y ver: no dice que es simple y honesto sino que lo muestra por medio de su manera de expresarse. Dicho en términos de Ducrot $^{2}$, la eficacia retórica del ethos "no tiene que ver con las apreciaciones elogiosas que el orador pueda hacer sobre su propia persona en el contenido de su discurso (...), se trata en cambio de la apariencia que le confieren la cadencia, una entonación calurosa o severa, la elección de las palabras o de los argumentos..." (1984, p201). El ethos queda así ligado al ejercicio de la palabra, al papel que le corresponde a su discurso y no al individuo real e independiente de su actividad discursiva (Amossy, 1999). En suma, el ethos se pone de manifiesto en el discurso por medio de las elecciones - tanto deliberadas como emocionales - que hace el sujeto de la enunciación, es decir, por medio de su forma de expresarse.

Desde este punto de vista, la apelación recurrente a ciertos campos del significado ubica la imagen del enunciador como asociada al grado de neutralidad de esos campos: $\mathrm{si}$ están referidos a un ámbito llano colaborarán en la configuración de una imagen calma o hasta reposada del enunciador; si aluden a un ámbito maravilloso o excepcional, colaborarán en la conformación de una imagen enfática o hasta excesiva. Así, la alusión repetida a un universo cotidiano como el de la cocina para dictar clases de escritura, por medio de expresiones como "sazonar las ideas con la pimienta retórica", "sofreír las frases", "una prosa sabrosa”, "aderezar las explicaciones”, "receta para escribir cartas", por ejemplo, puede colaborar en la construcción de la imagen de un enunciador sosegado (y, seguramente, original, por el tipo de asociación infrecuente).

Desde luego, esas alusiones no funcionan de manera aislada. De hecho, la recurrencia de alusiones a ciertos campos de significado suele aparecer acompañada de estrategias discursivas, de rasgos genéricos e incluso de gestos que corroboran esa imagen que se ha configurado. En consecuencia, el ethos de ese profesor que imaginamos como un educador reflexivo será ratificado o rectificado por el empleo de otras estrategias discursivas y también por su accionar concreto en el aula. Lo que queremos decir, en todo caso, es que la selección de esos campos de significado no resulta fortuita y, por el contrario, contribuye en la configuración de la imagen del enunciador.

Es más, en los términos de Maingueneau (1999), el ethos es la instancia subjetiva que se manifiesta a través del discurso, esto es, que se manifiesta como una voz, como un cuerpo enunciante, especificado históricamente e inscripto en una situación que su misma enunciación presupone y valida progresivamente. Una voz y un cuerpo que se fundamentan en un conjunto difuso de representaciones sociales valorizadas o desvalorizadas, sobre las cuales se apoya la enunciación y a las que la propia enunciación, a

\footnotetext{
${ }^{2}$ Ducrot (1984), retoma por primera vez el término aristotélico ethos en nuestros tiempos. A partir de allí, comienza a ser utilizado con sentidos aproximadamente equivalentes por distintos autores como, por ejemplo, Maingueneau o Amossy.

${ }^{3}$ Estas son frases usadas por Daniel Cassany en su libro La cocina de la escritura (1997).
} 
su vez, contribuye a transformar o a consolidar. Por ello, sostenemos, la recurrencia de alusiones a los mismos campos de significado constituye una estrategia clara en la búsqueda de consolidar una cierta imagen discursiva. Y esa recurrencia enviste a esa imagen de ciertas condiciones asociadas a la neutralidad o a la intensidad de los campos de significado que aparecen mencionados en el propio discurso.

\section{Los tópicos y la modalización tópica}

Siguiendo a Amossy y Herschberg Pierrot (2005), diremos que, inicialmente, los tópicos se relacionan con los topoi koinoi o lugares comunes de la antigüedad. En Aristóteles, son categorías formales de argumentos de alcance universal que están provistos de un cierto contenido.

Integrados a la inventio, primera parte de la construcción del discurso, son un método de razonamiento y, con el tiempo, una reserva de argumentos tipo, de procedimientos de ampliación y de desarrollos ya elaborados de ideas, algo así como catálogos de conceptos organizados por rubros. De ese modo, el tópico constituye en la Antigüedad Clásica un medio de persuasión: el acuerdo sobre los valores que los tópicos cargan es una prueba de la validez de los argumentos y es, además, una forma de garantizar el éxito del discurso en tanto discurso persuasivo.

Durante la Edad Media y la Moderna, sin embargo, los tópicos fueron gradualmente más y más rechazados como fórmulas banales, trilladas y hasta vacías; pero, ya en el siglo $\mathrm{XX}$, volvieron a atraer la mirada de los estudiosos, básicamente la de los sociólogos y lingüistas.

En los términos de Escobar (2006) — quien, de hecho, se refiere al tópico como figura literaria-:

El tópico puede utilizarse en todo tipo de discurso literario y se inserta, en principio, en una estructura demostrativa. Su función es argumentativa ( ...), es siempre el tópico — desde su vigencia tradicional - el que aporta la prueba al argumento concreto aducido por el autor previamente. (Escobar, 2006, p. 11)

Lo que confirma que, incluso en la literatura, el tópico funciona con un valor claramente persuasivo, en el sentido de que confirma lo dicho desde el lugar de lo aceptado tradicionalmente.

Visto esto, diremos que, para nosotros, los tópicos son campos de significado plausibles a los que se asocian determinadas ideas con el objeto de producir adhesión por parte de los destinatarios. O, tal cual sostiene Vitale (2007, p48), son "elementos de la Doxa considerados evidentes, fuera de discusión, por un grupo social determinado". 
En este sentido, podría tomarse el tópico de la caída hacia el abismo como una figura que representa la existencia de una serie de etapas en dirección a la destrucción o la quiebra del país, tópico elegido por cierta prensa argentina — como muestra Vitale (2007) - para provocar la adhesión a los golpes de estado que se sucedieron entre 1930 y 1976 en la Argentina. O podría tomarse el tópico de la enfermedad terminal, el "cáncer" de una determinada orientación ideológica dominante, para demostrar la necesidad de recurrir al "médico", el líder revolucionario, que pueda curar a la nación.

Ahora bien, a pesar de que el concepto de tópico ha sido usado en términos de su asociación con un campo semántico específico, pretendemos aquí hablar del tópico según su inserción en una gradación binaria. De hecho, para nosotros, cada tópico puede ubicarse en una escala de tipo ordinario-extraordinario. En este sentido, hablar de la cocina — como hacíamos más arriba - no es más que hablar de un espacio ordinario. Hablar de un abismo o de una enfermedad terminal, por el contrario, no es sino hablar de un espacio extraordinario.

Sobre esta base, entonces, quisiéramos introducir la noción de modalización tópica. Como se sabe, el término modalización refiere a la manifestación de la subjetividad del enunciador por medio de exhibir una cierta actitud respecto de su enunciado y de su interlocutor. Esa actitud es exteriorizada a través de mecanismos prosódicos - como una entonación enfática - , o morfológicos — como el uso de un subjuntivo pasado en lugar de un indicativo, al modo de "Mozart, quien vivió/viviera en el siglo XVIII..."一, o sintácticos - como el uso de una oración impersonal con sujeto arbitrario de segunda persona (Hernanz, 1990), al modo de "Cada vez tengo más preocupaciones con mis hijos; y es que si tú no los cuidas, no los cuida nadie ..." — ${ }^{4}$, o léxicos — como el uso de términos afectivos (Kerbrat, 1986), del tipo de "deprimente" o "adorable" - e incluso pragmáticos - como el empleo de marcadores de enunciado y de enunciación, como "probablemente" y "francamente" —. Parafraseando a Hyland (1998) que se refiere a la modalización epistémica ${ }^{5}$, diremos que estos mecanismos pueden ser clasificados según sea que promueven uno de tres tipos distintos de lecturas ${ }^{6}$ : lecturas atenuadas, lecturas neutras o lecturas intensificadas.

\footnotetext{
${ }^{4}$ El sujeto arbitrario de segunda persona es aquel que no apunta a un interlocutor concreto sino que funciona con un valor de sujeto indeterminado o, en muchos casos, que encubre una primera persona singular, como en Hoy tengo uno de esos días en que estás deprimido sin saber por qué (Gómez Torrego, 1998, p. 13).

${ }^{5}$ Para Hyland (1998), la modalización puede evidenciarse por medio de hedges o atenuadores, ítems léxicos o marcas morfológicas que permiten disminuir la imposición de los enunciados asertivos, o por medio de boosters o reforzadores, expresiones o marcas que permiten aumentar la imposición de los enunciados asertivos; la ausencia de unos y otros colabora en la configuración de enunciados neutros.

${ }^{6}$ Es decir, tres tipos de interpretaciones.
} 
A estos dispositivos proponemos agregar la clase tópica, entendiendo que los tópicos evocan universos ordinarios o universos extraordinarios ${ }^{7}$. Así, la evocación de universos ordinarios funciona en el discurso de manera neutra, tal cual lo hacen ciertos mecanismos prosódicos o morfológicos como el uso de una entonación no enfática o el uso del indicativo respectivamente. La evocación de universos extraordinarios, por su parte, funciona de manera intensificada, tal cual lo hacen ciertos dispositivos léxicos o sintácticos como el empleo de términos afectivos o el de un sujeto arbitrario de segunda persona.

$\mathrm{Al}$ igual que las demás estrategias de modalización, la modalización tópica contribuye en la configuración del ethos del enunciador, en términos de otorgarle un carácter más llano o un carácter más enérgico. Y su concurrencia con otras estrategias determina, en definitiva, la imagen que se construye a partir de su discurso.

Para aplicar estas nociones a un caso concreto, en lo que sigue, analizaremos los tópicos recurrentes en los discursos seleccionados de Eva Perón.

\section{Tópicos recurrentes en los discursos del $1^{\circ}$ de mayo}

El discurso de Eva Perón apela de manera estratégica a los tópicos. Así, por ejemplo, la oradora suele presentarse a sí misma como "un puente de paz", utilizando el tópico del puente como imagen que lleva desde una orilla (el colectivo formado por los trabajadores, el pueblo) hasta la otra (el líder natural, Perón):

1. Yo, que he tratado de ser un puente de amor entre el pueblo y el general Perón (1950, p. 13$)^{8}$.

2. ... trataré de ser a diario un puente de amor entre ustedes y el general Perón (1950, p. 20).

3. ... estoy con ustedes para ser ese puente de amor y de felicidad que siempre he tratado de ser entre ustedes y el líder de los trabajadores (1950, p.5).

y suele referirse a su función y a la del general Perón como una función "sanadora":

4. ... quiero ser una mujer más, confundida con el corazón de mi pueblo para sentir sus latidos, para auscultar sus inquietudes (1950, p. 16).

5. Hay mucho dolor que mitigar; hay que restañar muchas heridas, porque todavía hay muchos enfermos y muchos que sufren (1952, p. 4).

6. He de estar noche y día trabajando por mitigar dolores y restañar heridas (1952, p. 6).

\footnotetext{
${ }^{7}$ No existen, creemos, universos subordinarios.

${ }^{8}$ Nombramos cada ejemplo por el año en que fue proclamado el discurso y el número de párrafo en el que aparece en ese discurso.
} 
en el sentido de que, como profesionales de la salud política, Perón y Eva han de ocuparse de curar los males de la Nación y apaciguar el dolor de los argentinos.

Incluso, suele referirse a la acción del contradestinatario (Verón, 1986) por medio del tópico de la noche:

7. ... cuando gobiernos egoístas los tenían sumergidos en la más oscura de las noches de la explotación (1950, p. 3).

8. La justicia social que proclamó nuestro ilustre líder, el general Perón, será una estrella en la noche de la desesperanza humana (1950, p. 9).

9. ... la opresión de los traidores de adentro y de afuera que en la oscuridad de la noche quieren dejar el veneno de sus víboras en el alma y en el cuerpo de Perón (1952, p. 1).

un tópico que alude a la oscuridad como noción afiliada tradicionalmente a lo malo, a lo tenebroso y a lo que amedrenta. En todos los casos, tanto cuando habla de lo positivo (la acción de Perón) como cuando habla de lo negativo (la acción de los opositores), apunta a campos hiperbólicos que refieren a emociones extremas, como el campo del dolor y el campo del temor.

Sin embargo, son dos los tópicos que nos interesan particularmente en el discurso de Eva, y nos interesan por la alta frecuencia con que aparecen en este corpus ejemplar y por el tipo de asociaciones semánticas que despliegan: el tópico de la batalla y el tópico de la religión.

Para mostrar esa recurrencia, agruparemos las ocurrencias efectivas en unidades tópicas, definiendo cada unidad tópica como "la realización concreta del tópico, en cuanto segmento aislado y reconocible, es decir, todo aquello que, en el contexto, contribuye directamente a la plena expresión conceptual del tópico en cuestión" (Escobar, 2006, p. 12).

\section{El tópico de la batalla}

Son tres las unidades tópicas que encarnan el tópico de la batalla: la relativa a la conformación de un ejército, la que se refiere a las acciones bélicas y la que concierne al resultado de la contienda. En cuanto a la primera, tenemos como ejemplos:

10. Yo he visto a este pueblo, a estas vanguardias descamisadas (1950, p. 14).

11. ... trataré de estrechar filas en todos los sindicatos argentinos (1950, p. 20).

12. ... que tiene por guía, por bandera y por único líder al general Perón. (1950, p. 21). 
13. ... está el espíritu y el corazón de los argentinos para servir de escudo en defensa de la vida de Perón (1952, p. 3).

14. ... esta legión de argentinos (1952, p. 6).

Obviamente, las expresiones legión (14), vanguardia (10) y estrechar filas (11) apuntan a la formación de las tropas que se dirigen al combate, mientras que escudo (13) alude a la defensa (que los peronistas deben ejercer en relación con la figura de Perón) y bandera (12) refiere aquí al símbolo que se reconoce en la batalla para seguirlo en la dirección apropiada. En este caso, el pueblo se asocia a un ejército en marcha guiado por su conductor, el general Perón.

Por su parte, la unidad tópica relativa a las acciones bélicas aparece representada en los segmentos:

15. ... conquistaron su derecho de libertad y de soberanía (1951, p. 4).

16. ... el pueblo humilde de la patria, que aquí y en todo el país está de pie y lo seguirá a Perón, el líder del pueblo (1952, p. 1).

17. ... iremos a hacer justicia por nuestras propias manos. (1952, p. 3).

18. ... luchamos junto con Perón (1952, p. 4).

19. Otra vez estoy en la lucha (1952, p. 4).

20. El enemigo acecha (1952, p. 7).

21. ... estando el pueblo alerta somos invencibles (1952, p. 7).

22. Los vendepatrias de dentro, que se venden por cuatro monedas, están también en acecho para dar el golpe en cualquier momento (1952, p. 7).

Verbos y expresiones como: luchar (18), conquistar (15) y acechar (20) o expresiones como estar de pie (16), estar en la lucha (19), estar alerta (21), estar en acecho (22), seguir al líder (16), hacer justicia por mano propia (17) y dar el golpe (22) remiten claramente a distintos momentos de la refriega: los momentos previos (estar alerta o en acecho, estar de pie), el avance sobre el enemigo (seguir al líder, ir a hacer justicia), el ataque propiamente dicho (dar el golpe), el desarrollo del combate (luchar) y el logro del objetivo (conquistar). Como puede apreciarse, el ejercicio político está presentado en estos discursos como una lucha con el adversario (el enemigo) que requiere de una actitud ofensiva con el propósito de ampliar y reafirmar el poder.

Finalmente, la unidad tópica que se refiere al resultado de la contienda:

23. ... los trabajadores festejan el triunfo del pueblo y de Perón (1951, p. 1).

24. ... lo siguieron, como se sigue solamente a una bandera, dispuestos a morir por ella o a triunfar con su victoria $(1951$, p. 5$)$.

25. ... para festejar la victoria del 17 de octubre de 1945 (1951, p. 5).

26. ... llorando a nuestros muertos en lugar de festejar la victoria (1951, p. 8). 
polariza los resultados en términos de victoria (24), (25), (26) y triunfo (23), (24) o muerte (24) y (26). En ningún segmento de nuestro corpus ejemplar (aunque aquí solo presentamos algunos ejemplos), se utiliza el término derrota: en efecto, como decimos, la antítesis se presenta como victoria/triunfo y muerte, pero nunca se menciona la derrota en estos discursos. Así, el festejo del $1^{\circ}$ de mayo solo aparece asociado con el carácter triunfal de la victoria y la condición heroica de la muerte por un ideal, pero no resulta relacionado con el fracaso o con la caída.

En suma, el pueblo peronista constituye un ejército que lucha por una causa justa y que, en esa lucha, puede triunfar o morir, nunca ser derrotado.

\section{El tópico de la religión}

En cuanto al tópico de la religión, reconocemos tres unidades tópicas. En primer lugar, podemos hablar de los segmentos que aluden a la condición religiosa de la fe y a la gloria:

27. El peronismo no se aprende ni se proclama, se siente y se comprende, ha dicho Perón. Es condición de fe (1950, p.7).

28. Es, en suma, fe hecha partido (1950, p. 7).

29. ... felicito a los humildes, a los descamisados, a los trabajadores, y por ello, muy fervorosamente la Confederación General del Trabajo, por esta fe (1951, p. 10).

30. ... levantar los ojos hacia el general Perón, porque no concebían el cielo sin su líder (1950, p. 15).

31. ... para los hombres y mujeres del mundo que quieran compartir con nosotros la gloria de un pueblo (1951, p. 2).

En efecto, la doctrina peronista aparece asociada en el discurso de Eva a una "condición de fe" (27), (28), (29), con un líder que está en el cielo como los santos, y por eso hay que levantar los ojos para verlo (30); esta condición determina que solo los que creen en el peronismo podrán compartir la gloria (31). En este sentido, la ideología peronista resulta encuadrada en un terreno espiritual, apartada de la imperfección de lo humano.

En segundo lugar, podemos hablar de la unidad tópica que refiere a la proclamación de lo sagrado:

32. ... una causa de esperanza que faltaba en la Patria, y que hoy el pueblo, en mil voces, proclama fervorosamente (1950, p. 7).

33. Para nosotros, Perón es sagrado (1950, p. 18).

34. Bendito sea Perón (1950, p. 1). 
35. Pueblo predestinado ha de ser el nuestro ... (1950, p. 2)

36. ... en este país bendito y prodigioso (1950, p. 4).

37. ... la gracia infinita de morir por la causa de Perón (1951, p. 10).

38. En nombre de las mujeres de mi patria he abrazado el apostolado de acompañar el general Perón (1949, p. 20).

La doctrina peronista se proclama con fervor (32), su líder es sagrado (33) y quien cree en esa doctrina es un elegido, está predestinado (35), recibe la gracia (37). Por su parte, Eva es la mensajera, ha abrazado el apostolado del general Perón (38) y Perón y la Patria son benditos (34), (36). Desde luego, términos como gracia, apostolado, bendición, predestinación y fervor se enlazan estrictamente con los léxicos específicos de los distintos cultos.

Por último, la unidad tópica relativa al sacrificio, entendido según su valor inicial de ofrenda a una deidad en señal de homenaje o expiación (DRAE), aparece también de manera explícita:

39. ... veo al general Perón quemar su vida en aras de la felicidad del pueblo trabajador argentino (1949, p. 12).

40. Yo sé que no habría un trabajador, un hombre humilde, una mujer auténticamente del pueblo que no diera la vida en aras de la felicidad de los argentinos y de la patria misma. (1949, p. 12).

41. ... unos deseos irrefrenables de quemar mi vida ... (1949, p. 20).

42. ... un patriota que está quemando su vida en la tarea (1950, p. 1).

43. Quiero que veáis en esta mujer, trabajadores de mi Patria, a una amiga leal y sincera a quien no le importa quemar su vida y su juventud en holocausto de una causa tan grande como es la causa del pueblo (1950, p. 21).

En efecto, expresiones como aras (39), (40), quemar la vida (39), (41), (42), (43) y holocausto (43) aluden de manera unívoca a los sacrificios rituales en los que la víctima es quemada en el altar. De acuerdo entonces con esta unidad tópica, realizada en los distintos ejemplos propuestos, la causa de la Patria exige el esfuerzo incondicional de sus líderes, pero también exige el compromiso incondicional del pueblo.

En definitiva, la doctrina partidaria aparece representada como un dogma religioso y, en tanto tal, sus lineamientos constituyen un credo indiscutible, proclamado como palabra divina por sus líderes y aclamado con devoción por el pueblo.

\section{Tópicos y ethos}


Si nuestra hipótesis es correcta, la alusión a determinados campos de significado, y no a otros, forma parte del programa del enunciador orientado a alcanzar su objetivo argumentativo.

Así, los discursos de Eva asocian la doctrina peronista a un acto de fe y la acción política a un combate, mientras que el pueblo peronista y sus dirigentes son vistos alternadamente como miembros de un ejército y de una grey religiosa. Más aún, hay segmentos discursivos en que los dos campos de significados se entremezclan, tal cual se ve en:

44. ... con nuestro grito de guerra, con nuestro grito de salvación: ¡la vida por Perón! (1951, p. 10).

45. ... ha levantado la bandera de redención y de justicia (1952, p. 1).

donde guerra y salvación (44) o justicia y redención (45) se amalgaman, como constitutivos de una especie de "sobrecampo" de significado que aúna el tópico de la batalla y el tópico de la religión.

En este sentido, el universo peronista y el accionar del gobierno son investidos explícitamente de los caracteres que corresponden a dos ámbitos hiperbólicos, tanto el de lo heroico como el de lo divino, en el sentido de que los protagonistas — es decir, Perón, Eva y el pueblo peronista - aparecen representados como héroes y como santos a la vez. Sin embargo, lo hemos dicho, la eficacia retórica del ethos no se relaciona con el tipo de apreciaciones que el orador pueda hacer sobre su propia persona en el contenido de su discurso: se trata, antes bien, del tipo de impresiones que puede provocar y de la imagen que ese discurso suscita.

Todo esto significa, por un lado, que los tópicos funcionan persuasivamente para promover la aceptación del contenido de lo dicho. En consecuencia, al asociar semánticamente a Perón y a sí misma con el mundo de lo bélico y con el mundo de lo divino, el discurso de Eva presenta un retrato de ambos como el propio de quien combate por una causa santa, y por ello tiene garantizado, como mínimo, el mérito. Desde este punto de vista, entonces, los tópicos usados en estos discursos funcionan persuasivamente como un argumento incuestionable, como la instancia de fundamentación que no necesita ser contrastada porque su validez es inherente a ella: no se critica a los héroes, no se pone en duda lo divino.

Pero significa además, por el otro lado - y este es el punto que nos interesa-, que, al invocar universos hiperbólicos que suscitan imágenes ubicadas en el extremo de una escala — como la del héroe y la del santo—, el discurso de Eva configura la imagen de un enunciador intenso, apasionado y vehemente. Así, la alusión a estos espacios extraordinarios asocia la figura del enunciador a una condición extrema, enfática y 
excesiva, si se quiere. En efecto, no parece probable que se viera a este enunciador que evoca mundos elevados y lejanos como un enunciador calmo, sosegado y reflexivo.

Eso sí, esta constatación no se da de manera aislada. De hecho, es sabido, los discursos de Eva configuran el ethos de un enunciador apasionado (Amaré 2008, Ramírez Gelbes en prensa) porque, sumadas a la modalización tópica, otras estrategias del discurso de Eva aparecen orientadas en la misma dirección. Como prueba de ello, analizaremos algunas de esas otras estrategias en lo que sigue.

\section{Estrategias discursivas y ethos}

Hemos dicho, lo recordamos, que estas asociaciones semánticas con espacios ordinarios o extraordinarios no suelen aparecer aisladas de otros recursos, como el empleo de ciertas expresiones o de determinadas estrategias, por ejemplo.

En el caso de los discursos de Eva, la alusión semántica a universos hiperbólicos —en nuestro caso, el de lo heroico y el de lo sagrado - resulta confirmada por el uso de estrategias de intensificación como el empleo de otros mecanismos de modalización de refuerzo (Hyland, 1998) y la axiologización (Kerbrat, 1986).

Tal cual hemos propuesto en otro lugar (Ramírez Gelbes en prensa), en los discursos de Eva, Perón siempre resulta exaltado:

46. ... el General Perón, el realizador, el visionario, el patriota (1949, p. 4).

47. Perón es sagrado, es la Patria (1950, p. 18).

como un sujeto formidable: visionario (46), patriota (46), sagrado (47), sinónimo de la Patria (47).

Por su parte, el prodestinatario (Verón, 1986) suele aparecer aludido ponderativamente, con términos intensificados y axiologización positiva:

48. ... el pueblo mantiene intactos los valores morales que nos legaron los grandes de nuestra patria (1949, p. 10).

49. Mis queridos descamisados; descamisados de mi Patria (1950: Saludo inicial).

50. ... los trabajadores argentinos, los gloriosos descamisados de la Patria ... (1950, p. 3).

51. ...para decirle al general Perón que los Trabajadores, la Confederación General del Trabajo, las mujeres, los ancianos, los humildes y los niños de la patria no lo olvidarán jamás, porque nos hizo felices, porque nos hizo dignos, porque nos hizo buenos... (1951, p. 6). 
52. ... felicito a los humildes, a los descamisados, a los trabajadores, y por ello, muy fervorosamente a la Confederación General del Trabajo, por esta fe, por esta lealtad inquebrantable a Perón (1951, p. 10).

El pueblo es descripto, efectivamente, como sostenedor de los valores (48), querido (49), glorioso (50), digno (51), feliz (51), inquebrantable (52). Y esa intensificación y esa axiologización se reiteran cuando habla de sí misma, mostrándose humilde o aludiendo al sacrificio personal y a su entrega a Perón:

53. Yo, la más humilde colaboradora del general Perón, pero también como una de las más fervorosas amigas de los humildes y de los trabajadores. (1951, p. 10)

54. ... iqué hubiera sido de la Patria y de los trabajadores sin Perón? Por eso damos gracias a Dios de que nos haya otorgado el privilegio de tenerlo a Perón, de conocerlo a Perón, de comprenderlo, de quererlo y seguirlo a Perón (1951, p. 9).

55. Estoy con ustedes para ser un arco iris de amor (1952, p. 5).

por medio de la indicación superlativa, "la más humilde colaboradora" (53), la actitud agradecida, "damos gracias a Dios" (54) o la figura idílica,"un arco iris de amor" (55).

En cuanto al contradestinatario, Eva presenta consistentemente a su adversario de manera intensificada, con subjetivemas axiológicos y afectivos -negativos, obviamente- :

56. ... la inercia de los gobiernos despóticos y oligárquicos sólo conocían el odio y las negaciones (1949, p. 17).

57. ... cuando la oligarquía sin patria ni bandera quiso dejarnos a nosotros también sin patria ni bandera, robándonos el derecho de seguirlo a Perón hasta la muerte... (1951,p.5).

58. ... contra la opresión de los traidores de adentro y de afuera, que en la oscuridad de la noche quieren dejar el veneno de sus víboras en el alma y en el cuerpo de Perón (1952, p. 1)

59. Yo le pido a Dios que no permita a esos insectos levantar la mano contra Perón, porque iguay de ese día! (1952, p. 2).

60. ...los que, vendidos por cuatro monedas, sirven a sus amos de las metrópolis extranjeras (1952, p. 2)

La asociación del adversario con expresiones como inercia (56), odio (56), negaciones (56), sin patria ni bandera (57), robándonos (57), opresión (58), veneno (58), víboras (58), insectos (59) o vendidos (60) deja a las claras el tratamiento negativo extremo que se le otorga. 
Pero la ocurrencia de estos intensificadores no se reduce a la descripción de los participantes discursivos. También se manifiesta por medio de la exaltación de las emociones:

61. Es con inmensa alegría que hoy festejamos el 1º de mayo, día del trabajador. (1949, p. 1).

62. ... y batiendo palmas para aclamar al Líder de los trabajadores (1949, p. 2).

63. ...él ama entrañablemente a sus vanguardias descamisadas (1950, p. 5).

64. ... no habrá desamparados definitivos, no habrá resentimientos interminables. (1950, p.9).

65. ... no ha traído sino luchas estériles y fratricidas (1950, p. 12).

66. ... ustedes, solamente ustedes, pueden dar a mis palabras el fuego, la fuerza infinita que yo quiero tener (1951, p. 5).

67. Yo no tengo elocuencia, pero tengo corazón; un corazón peronista y descamisado, que sufrió desde abajo con el pueblo y que no lo olvidará jamás, por más arriba que $\operatorname{suba}(1951$, p. 6).

Así, la alegría (61) por la celebración es inmensa (61), tanto que incita a los presentes a batir palmas (62) para aclamar (62) a quien los ama entrañablemente (63), a quien conseguirá que no haya desamparados definitivos (64) ni resentimientos interminables (64), a quien ha terminado con las luchas estériles y fratricidas (65); por eso, las palabras de Eva tienen fuego (66), tienen una fuerza infinita (66) aunque no tengan elocuencia (67).

Como se ve, los discursos de Eva aparecen siempre axiologizados, intensificados por medio de las reiteraciones y de la suma de epítetos, realzados por un uso exuberante de intensificadores (Hyland, 1998) y subjetivemas evaluativos y afectivos (Kerbrat, 1986), y consistentes en las posiciones que otorgan a los distintos destinatarios y a la propia Eva.

Debemos hacer notar, todavía, que estos rasgos léxicos se añaden a otros mecanismos de modalización, como una entonación enfática:

68. ... porque iguay de ese día! (1952, p. 2).

69. ...vengo a unirme a ustedes para decirle a nuestro líder, con todo el corazón, "PPresente, mi general!" (1950, p. 22).

como la graduación de lo no graduable:

70. Quiero terminar con una frase muy mía ... (1949, p. 21).

como la referencia a un sujeto singular con valor genérico: 
71. ... te he visto a ti, mujer descamisada ... (1950, p. 13)

72. Te he visto a ti, descamisado de todos los octubres ... (1950, p. 14).

como la repetición de los sintagmas:

73. Hoy viene la masa trabajadora argentina a rendir homenaje al general Perón; hoy viene la masa trabajadora argentina a festejar este $1^{\circ}$ de mayo ... (1949, p. 5).

74. Luchamos por la independencia económica, luchamos por la dignificación de nuestros hijos, luchamos por el honor de una bandera y luchamos por la felicidad de este glorioso pueblo de descamisados (1950, p. 12).

o como el empleo de preguntas retóricas:

75. ¿Cómo podríamos las mujeres argentinas desertar de esta causa, que es la causa de todos? ¡Nunca! (1950, p. 11).

76. Pero, ¿qué hubiera sido de la Patria y de los trabajadores sin Perón? (1951, p.9).

En suma, el conjunto de estrategias de modalización de refuerzo conforma una imagen consistentemente intensificada: el ethos de un enunciador ardiente, impetuoso y acometedor; o, tal cual sostiene Amaré (2006, p2), el ethos de un sujeto capaz de interpelar el "fondo oscuro y pasional de las masas".

\section{A modo de conclusión}

El orador compone su ethos sobre las representaciones colectivas que sabe positivas a los ojos de su audiencia, pero que son también susceptibles de producir en ella la impresión adecuada a las circunstancias conforme a las exigencias de su proyecto argumentativo. Así, las estrategias discursivas empleadas contribuyen a la configuración de ese ethos, sean estas más relativas a la forma - como el empleo de cierta entonación o de determinadas estructuras —, sean estas más relativas al contenido — como la alusión a determinados campos de significado-.

En este trabajo, hemos mostrado que la evocación de universos hiperbólicos, como el de la batalla o el de la religión, que suscitan imágenes asociadas a los héroes y a los santos, constituye un mecanismo de refuerzo más en el discurso de Eva Perón. Este mecanismo, que hemos llamado modalización tópica, no aparece aislado sino, antes bien, solidarizado con otros dispositivos que construyen un discurso enfático: el empleo de términos evaluativos y afectivos, la repetición de palabras o de estructuras, el recurso a las preguntas retóricas, entre otros. 
Por ello, los discursos que Eva Perón produjo para el $1^{\circ}$ de mayo configuran consistentemente - y a lo largo de los cuatro años en los que se desarrollan - la imagen de una mujer enérgica, apasionada y extrema. Una mujer vehemente y combativa. Una mujer, en fin, que solo puede ser definida por calificativos hiperbólicos, tal y cual lo muestra la pervivencia histórica de su propia leyenda.

\section{Referencias bibliográficas}

Amaré, Mónica. (2008). Lecturas de la convocatoria partidaria hecha por el Partido Justicialista para las elecciones de noviembre de 1951. Ponencia presentada en el congreso El peronismo. Políticas culturales (1946-2006). Instituto Superior Octubre. En http://www.unsam.edu.ar/home/material/cabildo.pdf

Amossy, Ruth. (1999). L'ethos au Carrefour des disciplines: rhétorique, pragmatique, sociologie des champs. En Amossy, R. (dir.). Images de soi dans le discours. La construction de l' ethos. París: Delachaux et Niestlé.

Amossy, Ruth y Anne Herschberg Pierrot. (2005). Estereotipos y clichés. Buenos Aires: Eudeba.

Artistóteles. (1998). Retórica, Madrid: Alianza.

Cassany, Daniel. (1997). La cocina de la escritura. Barcelona: Paidós.

Ducrot, Oswald. (1984). El deciry lo dicho. Buenos Aires: Hachette.

Escobar, Ángel. (2006). El tópico literario como forma de tropo: definición y aplicación. En Cuadernos de Filología Clásica. Estudios Latinos 26, № 1, 5-24.

Gómez Torrego, Leonardo. (1998). La impersonalidad gramatical: descripción y norma. Madrid: Arco Libros.

Hernanz Carbó, Maria Lluisa. (1990). En torno a los sujetos arbitrarios: la 2a persona del singular. En Demonte, V. y B. Garza Cuarón (eds.): Estudios de lingüística de España y México. México: Universidad Nacional Autónoma de México, 151-178.

Hyland, Ken. (1998). Hedging in Scientific Research Articles. Amsterdam/Philadelphia, John Benjamins Publishing Co.

Kerbrat Orecchioni, Catherine. (1986). La Enunciación. De la subjetividad en el lenguaje. Buenos Aires: Hachette.

Maingueneau, Dominique. (1999). Ethos, scénographie, incorporation. En Amossy, R. (ed.), Images de soi dans le discours. La construction de l'éthos, París, Delachaux et Niestlé, 75-102.

Ramírez Gelbes, Silvia. (en prensa, septiembre/octubre 2009). De Eva a Cristina. Ethos y discurso politico. Ponencia presentada en el Pentálogo CISECO, Transformaciones de la mediatización presidencial: cuerpos, relatos, negociaciones, resistencias. Japaratinga.

Verón, Eliseo. (1987). La palabra adversativa. En E. Verón et al. El discurso político: lenguajes y acontecimientos. Buenos Aires: Hachette.

Vitale, Alejandra. (2007). Prensa escrita argentina y autoritarismo. El tópico de la caída hacia el abismo (1930-1976). En $P d G$ 4: 47-62 